\title{
Oral vesiculobullous lesions: Consider the platelets
}

Clare Steel, Lorna Mann, Richard Crosher ${ }^{1}$

Senior House Officer in Oral and Maxillofacial Surgery, ${ }^{1}$ Consultant in Oral and Maxillofacial Surgery, Rotherham General Hospital, Sheffield, UK
Address for correspondence: Dr. Clare Steel Senior House Officer in Oral and Maxillofacial Surgery, Rotherham General Hospital, Sheffield, UK. E-mail: clare.steel@hotmail.co.uk

\section{ABSTRACT}

Oral vesiculobullous lesions or "blood blisters" can be found on a routine dental examination and may have many causes. Trauma is often the first diagnosis followed by a variety of bullous conditions, such as pemphigus and pemphigoid. Using a case report, we highlight the other, more serious, possibility of idiopathic thrombocytopenic purpura (ITP) to raise awareness to the General Dental Practitioners and the need for prompt treatment.

Key words

Oral medicine, oral mucosa, oral trauma

\section{INTRODUCTION}

Oral vesiculobullous lesions or "blood blisters" are a common find, following trauma to the oral mucosa. Other causes include bullous conditions such as pemphigus or pemphigoid, which may warrant a referral to secondary care.

Blistering in the case of a mucocutaneous disease has been discussed in great depth in dental literature; ${ }^{[1]}$ however, another more serious cause is idiopathic thrombocytopenic purpura (ITP), which is less well reported and can be an acute risk to life. ITP is due to immune mediated shortened circulating platelet survival. This diagnosis can only be given upon exclusion of other causes of thrombocytopenia, such as leukemia, aplastic anemia, and infectious mononucleosis as well as some drug reactions. ${ }^{[2]}$

Symptoms of ITP include petechiae, superficial ecchymosis, and mucosal bleeding. A rare but serious complication is intracranial hemorrhage which is found in those with very low platelet counts. This is seen in less than $1 \%$ of sufferers. ${ }^{[2,3]}$

This case report describes the management of a 58-year-old male who presented with a sudden onset

\begin{tabular}{|l|l|}
\hline \multicolumn{2}{|c|}{ Access this article online } \\
\hline Quick Response Code: & Website: \\
\hline & www.ejgd.org \\
\cline { 2 - 3 } & \\
\hline
\end{tabular}

of oral blood blisters with no apparent cause. Further investigations led to a diagnosis of ITP. We discuss the causes, management, and possible risks associated with this condition and seek to raise awareness of ITP.

\section{CASE REPORT}

A 58-year-old male presented to the Accident and Emergency department complaining of a sudden onset of blood blisters in the mouth and associated bleeding, which he noticed on his pillow on waking. The patient wasn't experiencing any pain and could not recall a history of trauma, although he had eaten salted crisps the previous day. There was no weight loss or symptoms consistent with meningitis. He was a nonsmoker, occasional drinker, and was otherwise fit and well, apart from taking Diclofenac for cervical spondylosis.

On examination intraorally, multiple black bullae were present on the buccal mucosa, tongue, floor of the mouth, and palate. The lesions ranged in size from $2 \mathrm{~mm}$ to $10 \mathrm{~mm}$ in width. On the left buccal mucosa, there were three smaller lesions. The right mucosa consisted of one large, tender lesion with a smaller lesion on the soft palate. The lesions were not actively bleeding but burst and oozed when palpated as shown in the two images below [Figures 1 and 2]. Extraorally, there was telangiectasia on the face and the nose. At this stage, the differential diagnoses included trauma to the oral mucosa, angina bullosa hemorrhagica, or bullous pemphigoid. Due to the size, nature of the intraoral lesions aprovisional diagnosis of angina bullosa hemorrhagica $(\mathrm{ABH})$ was given. This connected with the mild trauma from consuming crisps and the spontaneous bursting of the lesions, although 


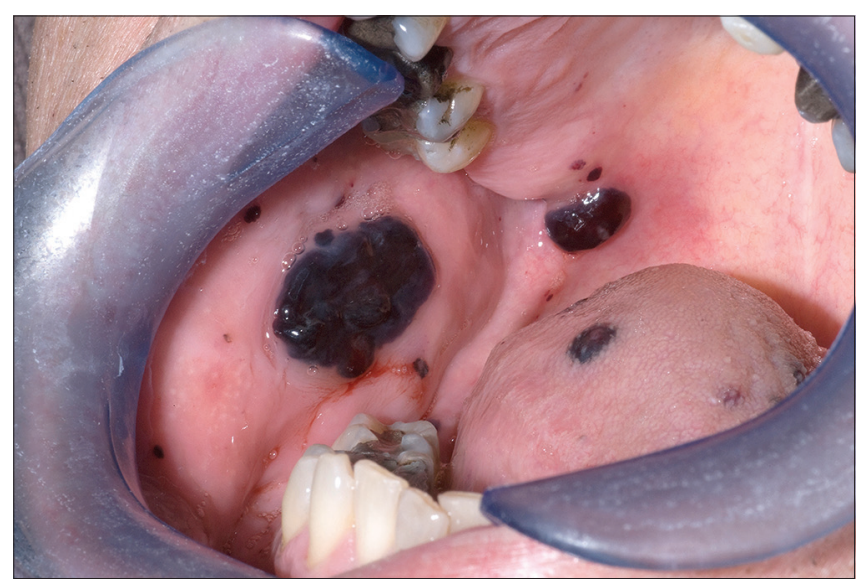

Figure 1: Image to show right buccal mucosal vesiculobullous lesions

the number and distribution of the lesions was not characteristic with most $\mathrm{ABH}$ cases. This diagnosis can only be made in the absence of blood dyscrasias and so further tests were conducted to reach a differential diagnosis. ${ }^{[4]}$

Upon receiving the results of the bloods taken in the emergency department, the diagnosis was drastically altered. The platelet count was $3 \times 10^{9} / \mathrm{L}$, substantially lower than the normal range of $150-400 \times 10^{9} / \mathrm{L}$. A blood film was examined where dysplasia and underlying malignancy were ruled out. Further examination revealed a purpuric rash on both lower limbs and bruising at the site of a previous venepuncture. Taking into account the blood dyscrasia and systemic extent of the bullae now witnessed, a final diagnosis of lesions secondary to thrombocytopenia triggered by mild oral trauma was given. This is known as ITP.

The hematology team subsequently took over the care of the patient, with immediate admission to the ward. The patient was started on a high dose of steroids (Prednisolone) and tranexamic acid, and Diclofenac was omitted. Hematuria was noted on day one and two; but each day, the platelet levels began to rise and after 3 days the level was $39 \times 10^{9} / \mathrm{L}$. After 1 week, the level had risen to $313 \times 10^{9} / \mathrm{L}$ and so steroid taper began. Intraoral healing was complete after 14 days and there were no lesions to be seen.

After 9 weeks the patient had made a full recovery and was no longer taking steroids. The platelet count was $214 \times 10^{9} / \mathrm{L}$. The patient continues to have review appointments with the hematology team every 4 months for monitoring purposes.

\section{DISCUSSION}

Platelets are formed in the cytoplasm of megakaryocytes, mainly contained within the bone marrow. The constant turnover of platelets maintains the levels

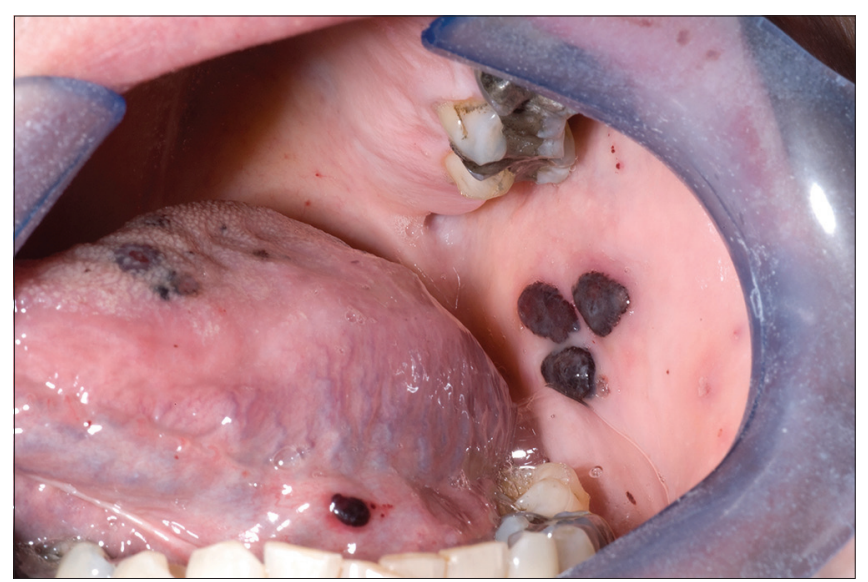

Figure 2: Image to show left buccal mucosa

at $150-400 \times 10^{9} / \mathrm{L}$. In thrombocytopenia, this delicate balance is disturbed by the attachment of immune complexes or viral antigens to the platelet which results in antibody binding and subsequent death. ${ }^{[2,3]}$

In the acute form, which usually affects children, the onset is abrupt and often follows infections such as mumps or rubella. Response to steroids is uncommon and remission is spontaneous in 1-2 weeks.

In the chronic form, there is a prolonged, insidious onset. Mucocutaneous hemorrhages, for example of the oral mucosa, spontaneous bruising and epistaxis are common findings. The condition can be present for many years. This form of the disorder responds well to steroid treatment. ${ }^{[2]}$

Treatment of idiopathic thrombocytopenia consists of a course of steroids such as Prednisolone or an immunosuppressant such as Azathioprine. If these measures fail, a patient may need a splenectomy for long-term remission. ${ }^{[4,5]}$

\section{CONCLUSIONS}

Oral vesiculobullous lesions can be a symptom of a variety of disorders ranging from trauma to bullous hemorrhagica lesions. In the case of trauma, a clinician may be tempted to review the patient in a few days, and a bullous diagnosis may only warrant an urgent referral to the local oral medicine department.

As this case shows that there can often be more serious causes of oral petechiae which must be eliminated immediately. If the patient is actively bleeding or has any other symptoms indicative of ITP such as bruising, lymphadenopathy, or splenomegaly, then a referral to the local oral and maxillofacial surgery (OMFS) or Accident and Emergency Department should be considered so that hematological input can be obtained quickly. 


\section{REFERENCES}

1. Darling M, Daley T. Blistering mucocutaneous diseases of the oral mucosa-a review: Part 1. Mucous membrane pemphigoid. J Can Dent Assoc 2006;71:851-4.

2. Howard MR, Hamilton PJ. Haematology an Illustrated Colour Text. $4^{\text {th }}$ ed. Churchill Livingstone; 2013.

3. Provan D. ABC of Clinical Haematology. $3^{\text {rd }}$ ed. Blackwell Publishing; 2007.
4. Rai S, Kaur M, Goel S. Angina bullosa hemorrhagica: Report of two cases. Indian J Dermatol 2012;57:503.

5. Bradbury C, Murray J. Investigating an incidental finding of thrombocytopenia. BMJ 2013;346:f11.

How to cite this article: Steel C, Mann L, Crosher R. Oral vesiculobullous lesions: Consider the platelets. Eur J Gen Dent 2014;3:167-9.

Source of Support: Nil, Conflict of Interest: None declared.

\section{New features on the journal's website}

\section{Optimized content for mobile and hand-held devices}

HTML pages have been optimized of mobile and other hand-held devices (such as iPad, Kindle, iPod) for faster browsing speed.

Click on [Mobile Full text] from Table of Contents page.

This is simple HTML version for faster download on mobiles (if viewed on desktop, it will be automatically redirected to full HTML version)

\section{E-Pub for hand-held devices}

EPUB is an open e-book standard recommended by The International Digital Publishing Forum which is designed for reflowable content i.e. the text display can be optimized for a particular display device.

Click on [EPub] from Table of Contents page.

There are various e-Pub readers such as for Windows: Digital Editions, OS X: Calibre/Bookworm, iPhone/iPod Touch/iPad: Stanza, and Linux: Calibre/Bookworm.

\section{E-Book for desktop}

One can also see the entire issue as printed here in a 'flip book' version on desktops.

Links are available from Current Issue as well as Archives pages.

Click on 1 View as eBook 